Research Article

Tuswan*, Achmad Zubaydi, Bambang Piscesa, and Abdi Ismail

\title{
Dynamic characteristic of partially debonded sandwich of ferry ro-ro's car deck: a numerical modeling
}

https://doi.org/10.1515/eng-2020-0051

Received Jan 06, 2020; accepted Mar 12, 2020

\begin{abstract}
The dynamic behavior of a partially debonded Ferry Ro-Ro's sandwich car deck is investigated by using commercial finite element software ABAQUS. Debonding in the car deck model is estimated by comparing the dynamic responses of the fully intact and damaged model of the bonding condition. The influence of the debonding ratio is investigated by free vibration analysis using Lanczos iteration method. The dynamic response of the car deck model is loaded with harmonic excitation and is examined in detail. The transverse displacements, velocities, accelerations, longitudinal strains, and phase portraits are investigated in the central point of the damaged area. To evaluate the effect of inserting the spring contact element during the dynamic analysis, both debonded models with and without spring contact elements are examined. From the report, it can be concluded that the dynamic analysis which relies on the modal analysis can be used to diagnose the possibility of debonding problem in the car deck structure. The natural frequencies of the debonded model decrease due to the presence of discontinuity in the debonded region. Further, the discontinuity also creates locally concentrated deformation and significantly affects the short-term time response.
\end{abstract}

Keywords: ferry ro-ro car deck, skin-to-core debonding, damage detection, dynamic analysis, finite element analysis

\footnotetext{
*Corresponding Author: Tuswan: Department of Naval Architecture, Institut Teknologi Sepuluh Nopember, Surabaya, Indonesia; Email: tuswan.18041@mhs.its.ac.id

Achmad Zubaydi, Abdi Ismail: Department of Naval Architecture, Institut Teknologi Sepuluh Nopember, Surabaya, Indonesia Bambang Piscesa: Department of Civil Engineering, Institut Teknologi Sepuluh Nopember, Surabaya, Indonesia
}

ə Open Access. ( 2020 Tuswan et al., published by De Gruyter. (cc) BY License

\section{Introduction}

For the purpose of improving competitiveness with other transportation modes, the application of lightweight material for ship structures, i.e., a hybrid sandwich, is essential. The hybrid sandwich material has been widely used in shipbuilding industries. It offers high bending stiffness to weight ratio and high damping properties compared to the conventional stiffened plate structure [1]. Due to the complexity of the design and manufacture process, it has been shown that hybrid sandwich materials are more prone to damage or defect. The significant distinctions between thickness and elastic moduli of the constitutive layers make them susceptible to interfacial crack or the loss of cohesion between the basic layers, which acknowledged as a skin-to-core debonding failure. Its partial damage may degrade the load-carrying capacity of the ship and significantly alters its dynamic characteristics [2-4].

At the early stage, these invisible local debonding can affect the behavior of the hybrid sandwich material. Therefore, a reliable assessment technique such as dynamic analysis of such ship structure is necessary to prevent the failures of the structure. The damage state associated with the presence of the debonding can be diagnosed by specific non-destructive damage detection method, i.e., numerical dynamic analysis [5]. This numerical dynamic analysis is usually associated with the use of finite element analysis and has been widely used to assess vibration in many structures $[6,7]$. The results of the dynamic finite element analysis can be used to strengthen the damage detection efficiency in the structural health monitoring system.

One of the difficulties in dealing with the dynamic response of debonded sandwich plates is to model their physical phenomena either within the framework of initial imperfection or material nonlinearities. Most research that investigated this problem used both linear and nonlinear approaches. One of the most recent approaches was based on the split-beam theory, where the decoupled layers were assumed to be able to penetrate each other or be constrained to move together [8-10]. To prevent overlap- 
ping between layers, the decoupled layers are linked by additional linear virtual spring elements and contact behavior between nodal surface are used [11-13]. This modeling condition would lead to strong nonlinear problem. Hence, a general dynamic analysis is often used to address this nonlinear contact behavior [13-16].

In $[17,18]$, piecewise linear spring elements are used to link the debonded region. Similar approaches were also used by [11] to investigate the free vibration behavior due to size, location, shape, and number of debonded regions, and variation of boundary conditions. In [19], the dynamic response of a debonded beam under a harmonic excitation was analyzed using a linear spring model. The modeled structures highlighted here were a composite sandwich with the shape of beams and plates.

In this paper, a linear dynamic finite element analysis will be carried out to investigate the effect of local damage (debonding problem) on the modal parameters of the car deck model which installed a sandwich plate system (SPS). SPS used in this analysis consists of steel faceplate and resin/clamshell core which have significant distinctions between thickness and elastic moduli between them. The free vibration, the steady-state analysis, and the modal dynamics are investigated to compare the healthy model and damaged model by using the ABAQUS finite element package [20]. To model the debonded problem, the models with a piecewise linear spring contact and without contact between debonded surfaces are compared. The car deck model is modeled with a damage ratio of $5 \%$ and $10 \%$. The effect of the debonded area is studied by comparing the dynamic properties of the structure: the natural frequencies, mode shapes, and time-domain data. In addition, the dynamic properties between the conventionally stiffened and sandwich car deck model will also be briefly discussed to analyze the effect of installing a sandwich panel and modifying the stiffener configuration of car deck models. The free vibration, the steady-state analysis, and the modal dynamics are investigated. The total of four different configuration models of the ship's car deck panel which installed SPS with various stiffener configurations is studied.

\section{Finite element modeling}

\subsection{D finite element modeling and treatment of the bonding and debonding problems}

The finite element analysis (FEA) plays an important role in the dynamic analysis, which can be used to evaluate the expected experimental data. For the case of experimental investigation, the dynamic response of the car deck panel can be excited by an external impact or embedded actuators. The data can be collected from the installed strain gauges and accelerometer. This setting enables the possibility to evaluate the structural behavior in real-time, and the structural health monitoring system of the structures can be established. However, to gain a better understanding of the dynamic behavior of the complex structure, numerical simulation should be carried out. In this research, the commercial finite element package ABAQUS is used. The procedure for FE simulation [21] can be divided into three steps: (1) preprocessing which involves modeling the geometry of the structures, meshing and assembling of the mass and stiffness matrices; (2) FE analysis to get the natural frequency, the frequency response function and timedependent data; and (3) post-processing to evaluate the desired output.

In the sandwich finite element model discretization of the car deck, the sandwich panel can be modeled using the layer-wise solid/shell element [22]. The use of shell elements can reduce the number of degree-of-freedoms (DOF). However, the stress in the thickness direction can be better modeled using solid elements. For that purpose, the outer layer (steel) is modeled using the eight-node quadrilateral shell element (SC8R) with reduced integration. The core layer is modeled using the eight-node hexahedral element (3D8I) with incompatible modes, as presented in Figure 1a.

Here, to model the debonding problem, a simplified modeling technique is used [11]. Several assumptions are adopted to describe the debonding issue: debonding is modeled as an artificial flaw embedded into interface zone between the faceplates and the core, the piecewise spring model in the debonded region is applied, debonding is assumed to be predetermined before the oscillations and to be constant during oscillations, and the shape of the debonded region is idealized with regular form (a regular circle plated).

The debonding is treated as an artificial imperfection at the interface layer between the two consecutive layers. This artificial imperfection is activated before the vi- 


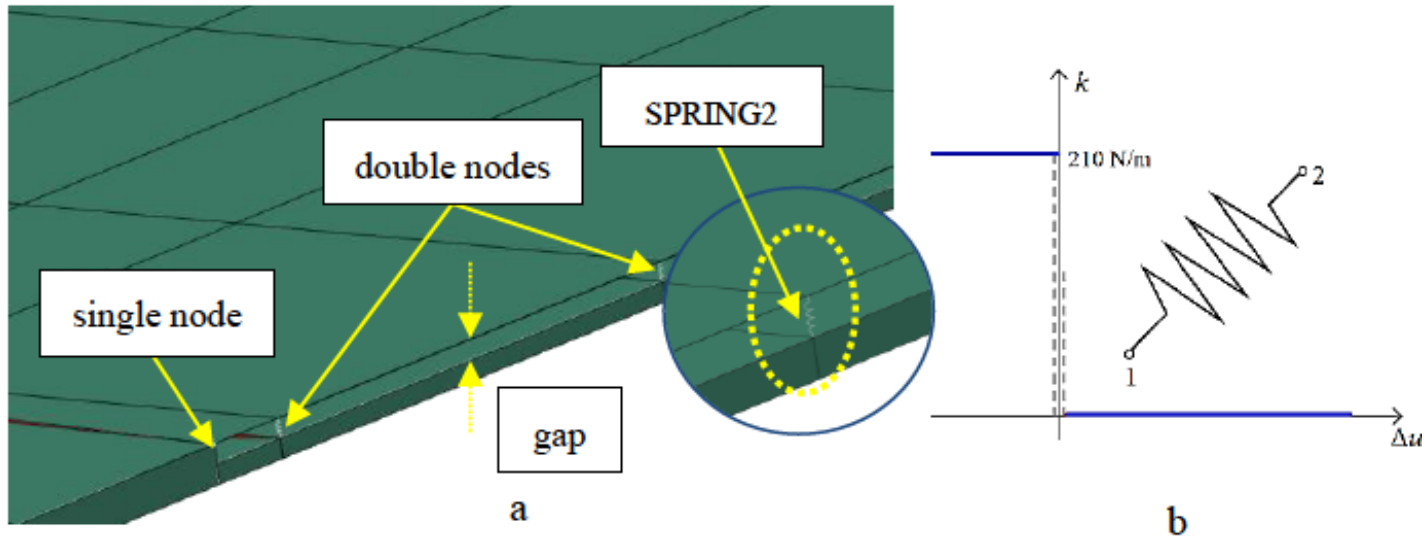

Figure 1: (a) Mesh detail in the debonded region (b) the behavior of spring element

Table 1: Model configurations of the car deck

\begin{tabular}{cccccc}
\hline Models & Plate Thickness $(\mathbf{m m})$ & \multicolumn{3}{c}{ Total of Stiffeners } & Total Weight (tonnes) \\
& & Strong Beam & Deck Beam & Deck Girder & \\
\hline Existing Model & 12 & 3 & 7 & 12 & 10.54 \\
Car Deck A & $4-20-4$ & 3 & 7 & 12 & 10.36 \\
Car Deck B & $4-20-4$ & 3 & 7 & - & 9.61 \\
Car Deck C & $4-20-4$ & 2 & 5 & - & 9.24 \\
\hline
\end{tabular}

brations analysis is carried out. During the pre-processor, the debonded area is modeled by creating a small gap (10\% of the steel plate thickness) between the core and the outer face of the sandwich structures. To prevent the possibility of the two surfaces overlapping each other, a piecewise spring element is used at the debonded surface area. In ABAQUS, 3D spring elements (SPRING2 available in ABAQUS) are used to connect the core and the outer face nodes in the debonded regions, as depicted in Figure 1a.

Two different contact options "with contact" and "without contact" spring elements were developed. To model spring element behavior, the spring stiffness is set to zero $(\mathrm{k}=0 \mathrm{~N} / \mathrm{m})$ when in tension and is set to a high value $\left(k=210 \times 10^{9} \mathrm{~N} / \mathrm{m}\right)$ when the force in compression and the relative displacement of the two nodes $(\Delta u)$ in the spring is zero. In fact, there is no literature which states the spring stiffness value of interface layer of proposed sandwich type. So, in this research, the spring element behavior is assumed to have similar spring stiffness as stated in [5]. In [5], In "with contact" model, the contact behavior is assumed by the free debonding model with setting a zero stiffness $(k=0 \mathrm{~N} / \mathrm{m})$ to the spring elements so the interfaces can move freely, while a nonzero stiffness value $\left(k=210 \times 10^{9} \mathrm{~N} / \mathrm{m}\right)$ causes the constrained debonding model between them that restrains the faceplate and the core from moving together $[8,9,23]$. In the model, both the ge- ometry and material behavior are set to constant during oscillations. The contact friction is set zero because the influence of the friction properties on the dynamic responses is insignificant [24]. For the fully bonded region, the multipoint constraint (MPC) contact is used.

\subsection{Reference model}

The model used as a reference is a Ferry Ro-Ro with the total car deck area $381.8 \mathrm{~m}^{2}$. The car deck panel comprises of two components: the stiffened plate and beam systems. The reference car deck is located parallel to the mid-body of the ship between the two bulkheads. Based on the previous sandwich application in the same model [25], the calculation of thickness configuration based on DNV-GL strength index criteria [26] results $4 \mathrm{~mm}$ thin faceplate and $20 \mathrm{~mm}$ thick core.

Three modified models of the car deck system, as illustrated in Table 1, had been investigated. In Table 1, the effect of adding a sandwich panel and varying the stiffener configuration of the car deck resulted in lower weight, which ranges from $2 \%$ to $12 \%$. In this study, the fully clamped car deck panel on all sides will be investigated. The dimension of the car deck model and the beam system are presented in Figure 2. The mechanical properties of the typical car deck model are presented in Table 2. 


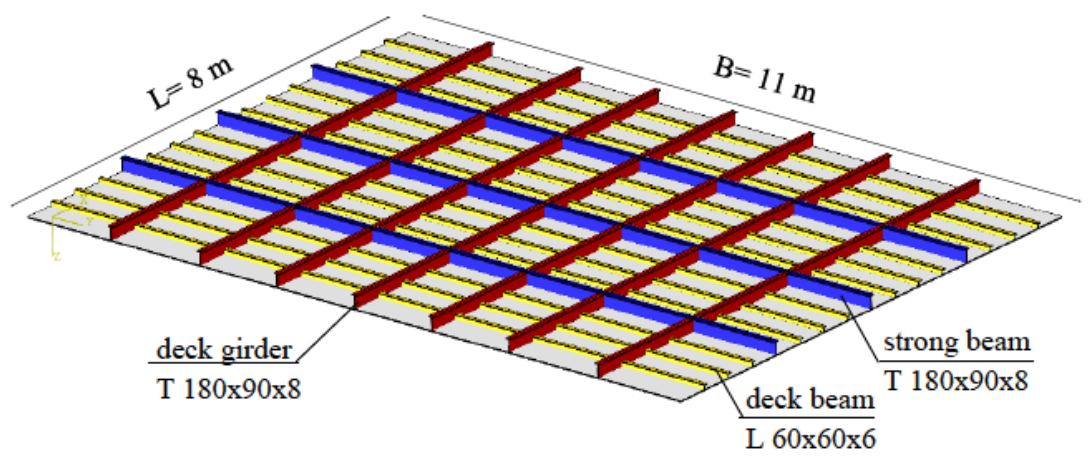

Figure 2: Reference existing model of existing stiffened car deck

Table 2: Mechanical constants

\begin{tabular}{ccccc}
\hline Materials & $\boldsymbol{\rho}\left(\mathbf{k g} / \mathbf{m}^{\mathbf{3}}\right)$ & $\mathbf{G}(\mathbf{M P a})$ & $\mathbf{E}(\mathbf{M P a})$ & $\boldsymbol{v}$ \\
\hline Steel & 7850 & $7.93 \times 10^{4}$ & $2.06 \times 10^{5}$ & 0.30 \\
Core (resin/clamshell) & 1465 & $1.27 \times 10^{2}$ & $3.31 \times 10^{2}$ & 0.30 \\
\hline
\end{tabular}

\subsection{Numerical Dynamic analysis}

The modal dynamic analysis is used to assess the behavior of both perfect and imperfect (with debonding defect) models of the car deck panel. It is expected that the debonding ratios can be used as the sensitivity indicator of the internal damage occurrence (discontinuities). For that purpose, the varying value of the debonding ratio is used. The planar size of prescribed debonding is defined by a damage parameter $\left(D_{\%}\right)$ denoting the ratio of the debonded region $\left(A_{d}\right)$ to the entire region of the sandwich plate $\left(A_{\text {total }}\right)$ as explained in Eq. 1 . The FE model of the perfectly clamped car deck panel containing a circular debonded region at the center is examined.

$$
D=\frac{A_{d}}{A_{\text {total }}} 100 \%
$$

For an initial analysis, the free vibration analyses are executed. Several studies explain that when the debonding between the faceplates and the core of the sandwich increases, the shear stress transfer area between the faceplates and the core will decrease. The decrease in the transfer area causes a decrease in the stiffness and strength of the sandwich. The analyses are executed using a linear perturbation load step within ABAQUS to analyze the first five natural frequencies and mode shapes of the model, where the Lanczos iteration method for eigenvalues extraction is used [20]. The frequency extraction procedure is to perform eigenvalue extraction and to calculate the natural frequencies and the corresponding mode shapes of a system.

Further, steady-state linear dynamic analysis is used to evaluate the linear response of a structure subjected to continuous harmonic excitation. Direct steady-state linear dynamic analysis procedure, in which the equations of steady harmonic motion of the system are solved directly without using the eigenmodes is used in this case. The frequency range between 1 and $35 \mathrm{~Hz}$ with the number of points 100 and bias 1 is used.

The modal dynamic procedure provides a time history analysis of linear systems. The excitation is given as a function of time: it is assumed that the amplitude curve is specified so that the magnitude of the excitation varies linearly within each increment. Since the load is time-dependent, the final response for each time is computed using the modal superposition method. The modal amplitudes are then integrated with respect to time, and the response is further calculated using these modal responses. For the model with harmonic excitation, the modal parameter can be obtained by applying the modal analysis, which much less expensive than using a direct integration method as in nonlinear dynamic analysis. In this analysis, the models are assumed to be excited at lower skin by an external periodic excitation with a constant frequency near the first mode. Finally, debonding existence can be diagnosed by comparing either the modal characteristics or time responses of healthy and damaged models. 


\section{Numerical result of dynamic analyses}

\subsection{Mesh convergence analysis}

Mesh convergence is an important issue to obtain accurate results with reasonable computational time. The use of coarse mesh can yield less stiff response of structures and higher natural frequencies. Therefore, several mesh sizes are used to get the optimum mesh-sizes. The mesh convergence analysis is carried out by investigating free vibration analysis to obtain the natural frequency of the first bending modes with ABAQUS. An existing car deck model, as depicted in Figure 1 with a fully clamped boundary condition in all sides deck, is used. The material properties used in this analysis are shown in Table 2.

The mesh convergence in the healthy car deck model and car deck model with debonding is also analyzed. The mesh sizes in the model are set from fine mesh at the debonded region and gradually becomes coarser away from the debonded area to reduce the computational time. For an example of mesh convergence result, it is depicted in Figure 3 that the solution converges for mesh sizes between $0.05 \mathrm{~m}$ and $0.02 \mathrm{~m}$. For the existing car deck model, the mesh element size $0.05 \mathrm{~m}$ with the number of elements and nodes is 51,000 and 56,000, respectively is used. Good agreement demonstrating successful modeling of eigenvibration problem can be noticed. Therefore, it validates the correctness of the model used in this analysis.

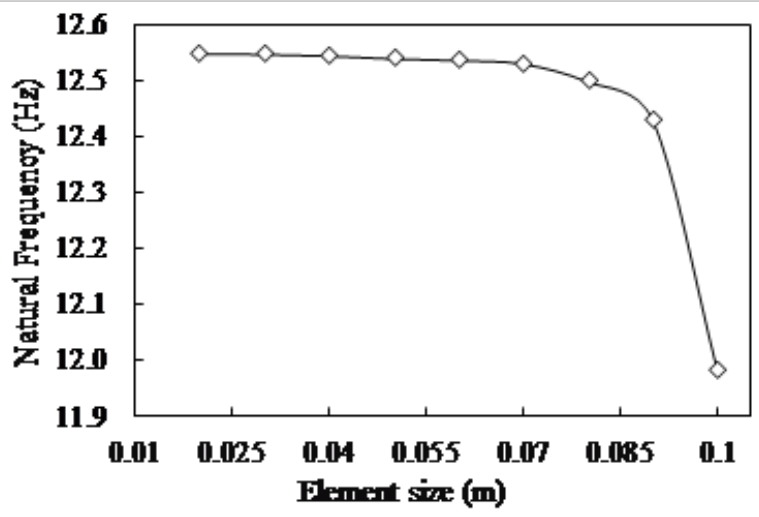

Figure 3: Mesh convergence in first bending mode

\subsection{Dynamic response comparison of the car deck panel models}

This section discusses the dynamic response comparison of the car deck panel model between the conventionally stiffened and three modified (installed with the proposed sandwich panel) car deck panel models. All the geometric and material properties' input is similar to the models used in the mesh convergence analysis. Table 3 shows the first five-mode shapes of the free vibration natural frequencies. As shown in Table 3, car decks A and B exhibit higher natural frequencies compared to car deck $\mathrm{C}$ and existing models. The use of sandwich material can reduce the weight of the panel [25] and higher stiffness compared to the existing model.

To gain more insight into the dynamic behavior of the car deck panel, modal dynamic analysis is used. A concentrated transverse harmonic loading at the central point of the lower face is applied with the magnitude and frequency of $49 \mathrm{kN}$ and $12.5 \mathrm{~Hz}$, respectively. The first mode frequency of the model is close to $12.5 \mathrm{~Hz}$. Figure 4 shows the output time history responses of the car deck panel. From Figure 4, it can be analyzed that the amplitude for each signal significantly differs between the existing and modified models. Car deck A and B have a lower signal amplitude compared to the existing model. On the other hand, car deck $\mathrm{C}$ has the highest signal amplitude. From the phase portrait data, the car deck A and B responses at the central point of the lower faceplate show trajectories that are smaller than the full intact model. Hence, the car deck $A$ and $B$ can be said to have more stiffness that the existing model. On the other hand, car deck $\mathrm{C}$ is less stiff than the existing model.

Table 3: Natural frequencies as functions of mode shapes of the car deck models

\begin{tabular}{lcccc}
\hline \multirow{2}{*}{ Mode } & \multicolumn{4}{c}{ Natural frequency $(\mathrm{Hz})$} \\
\cline { 2 - 5 } & $\begin{array}{c}\text { Existing } \\
\text { Model }\end{array}$ & $\begin{array}{c}\text { Car Deck } \\
\text { A }\end{array}$ & $\begin{array}{c}\text { Car Deck } \\
\text { B }\end{array}$ & $\begin{array}{c}\text { Car Deck } \\
\text { C }\end{array}$ \\
\hline 1 & 12.55 & 13.23 & 13.49 & 12.11 \\
2 & 18.08 & 19.20 & 18.93 & 18.07 \\
3 & 28.52 & 30.12 & 28.37 & 26.17 \\
4 & 29.98 & 30.89 & 30.68 & 27.21 \\
& 32.27 & 33.62 & 32.56 & 28.74 \\
\hline
\end{tabular}


a

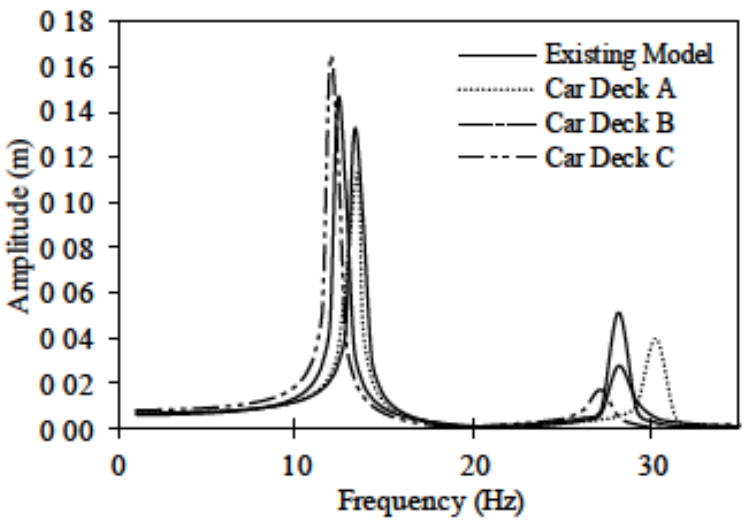

C

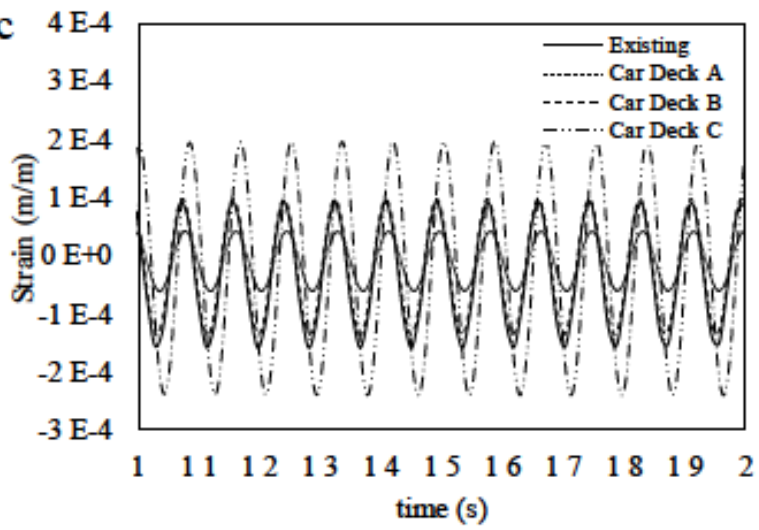

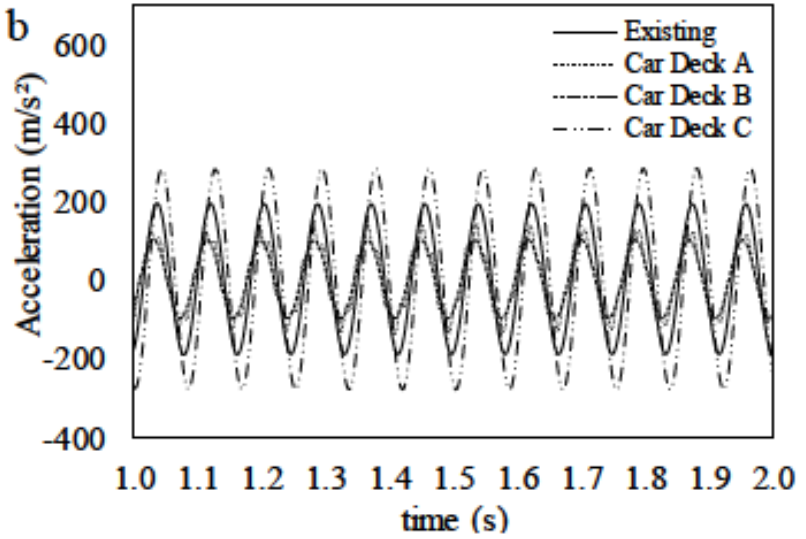

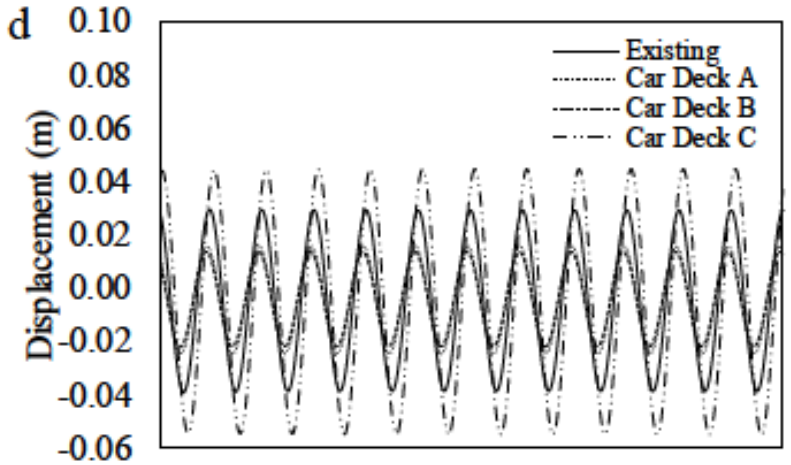

$\begin{array}{lllllllllll}1.0 & 1.1 & 1.2 & 1.3 & 1.4 & 1.5 & 1.6 & 1.7 & 1.8 & 1.9 & 2.0\end{array}$ time (s)
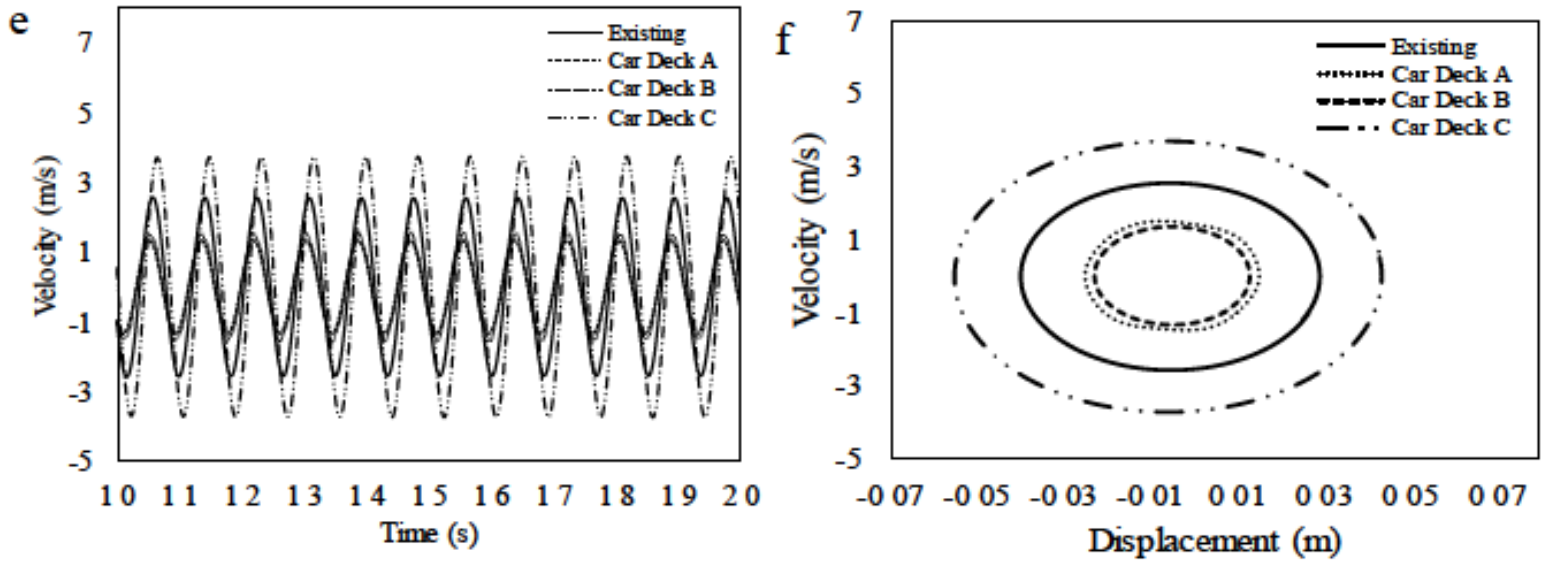

Figure 4: (a) FRF, time history responses: (b) acceleration, (c) strain, (d) displacement, (e) velocity, (f) phase portrait

\subsection{Effect of the debonding ratio}

This section investigates the effect of the debonding ratio of car deck B. The car deck model is modeled with a damage ratio of $5 \%$ and $10 \%$. The damage ratio is computed by taking the ratio of the debonding area to the total surface area of the sandwich plate. The free vibration analysis model is used. Both with and without contact conditions are evaluated. To prevent overlap between layers, spring elements with contact behavior as previously described are used.
Figure 5 shows that the free vibration response is affected by the presence of the imperfection (debonding defect) and significantly alter the natural frequencies in higher modes. In the lowest mode, the natural frequencies also affected by imperfection but not as sensitive as higher modes. One of the interesting findings is that the natural frequency of the model with $10 \%$ debonded area is slightly higher compared to the full intact model. This phenomenon is called the local thickening phenomenon [27, 28] which causes the cross-over phenomenon. 


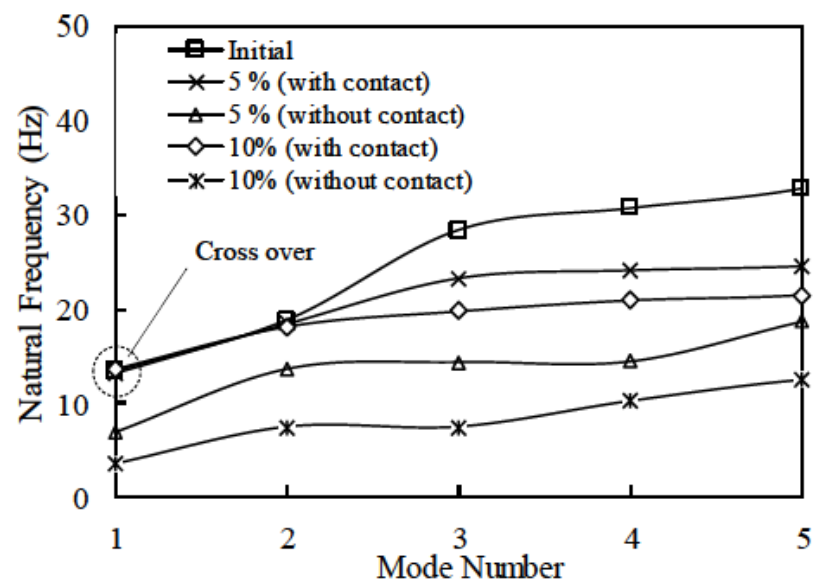

Figure 5: Numerical eigenfrequencies as a function of mode shape of models

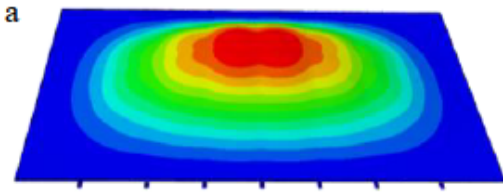

$1^{\text {st }}$ mode

b

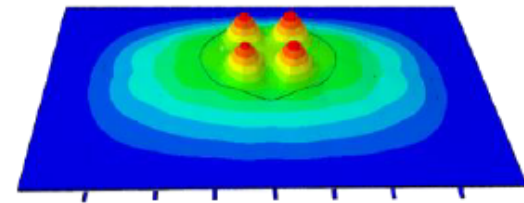

$1^{\text {st }}$ mode

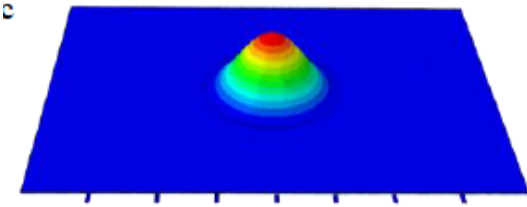

$1^{\text {st }}$ mode

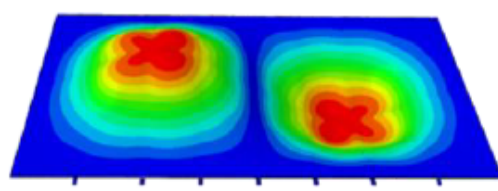

$2^{\text {nd }}$ mode

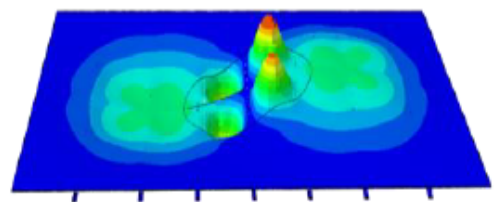

$2^{\text {nd }}$ mode

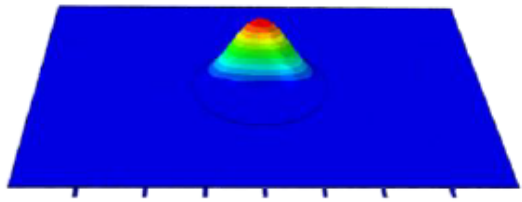

$2^{\text {nd }}$ mode

Figure 6: The first and second vibration modes: (a) initial model, (b) $10 \%$ debonding with contact (c) $10 \%$ debonding without contact

In Figure 5, the model with the contact was neglected shows lower natural frequencies which may not be the correct solution. In [21], this problem has been analyzed and further in [29], the natural frequencies and mode shapes are found to be almost insensitive. Hence, it can be concluded that the debonding effect can affect natural frequencies and is mode dependent. Moreover, the presence of debonding defect has a significant effect on the natural frequencies.

Figure 6 shows the modes shape deformation of the panels. The mode shapes of the debonded model show that the distortion of the mode shapes does occur locally in the damaged region. To further study the effect of debond- ing defect at the surface between the layers, time-history analysis of the car deck B with concentrated periodic load at the central point of the lower faceplate is investigated. The output time responses being recoded are the transverse displacement, velocities, accelerations, and longitudinal strains.

Figure 7 shows the time history responses between the fully intact and damaged models. Similar findings as in the free vibration analysis where the amplitude response for all models does vary significantly. The phase portrait motion depicted in Figure 7 shows that the damaged models do have a larger space trajectory than the full intact model. The larger the defect area, the space trajectory be- 

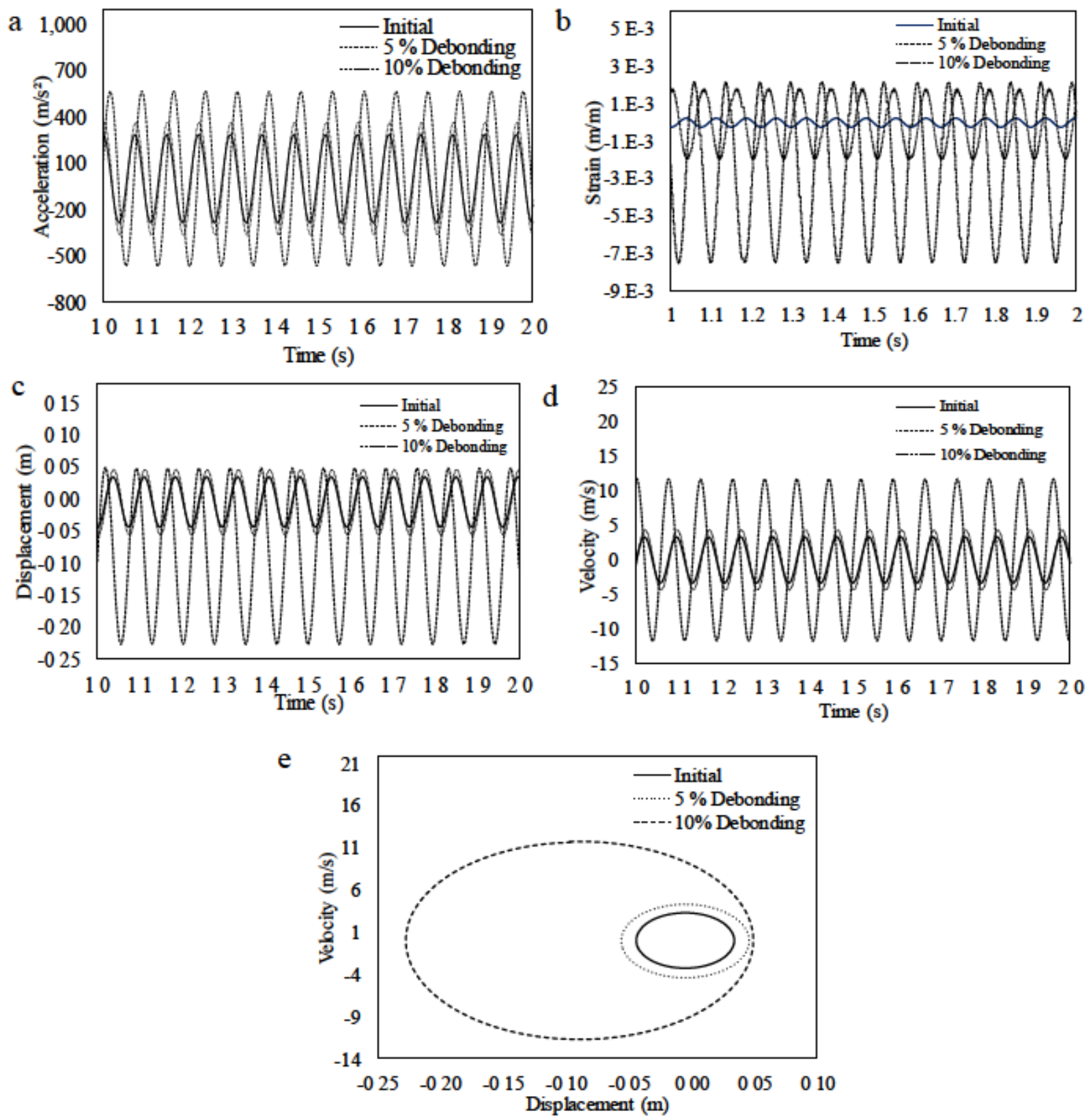

Figure 7: Time history outputs: (a) acceleration, (b) strain, (c) displacement, (d) velocity, (e) phase portrait

comes wider, and the origin of the space trajectory shifted. For 5\% debonding ratio, the origin of the space trajectory does look to coincide with the fully intact model. Hence, it would be interesting to find out the corresponding debonding ratio value at the onset of the shifting of the origin in the space trajectory. These larger space trajectories do represent the decrease in the panel stiffness due to debonding defect and all the responses amplitude of the model with defect show larger values than the intact model. In addition, it was found that the strain responses are one of the most sensitive responses among all responses recorded.

\section{Conclusion}

The paper had discussed the effect of installing a sandwich panel in the car deck on the dynamic response. A total of four configuration models had been developed. Finite element software ABAQUS was used in this analysis. It could be concluded that the application of sandwich material in Ferry Ro-Ro's car deck increased the stiffness of the structure. It could be recognized that car deck A and B are stiffer than the existing model. Meanwhile, car deck $\mathrm{C}$ was less stiff than the existing one. 
Furthermore, the effect of the debonding ratio on a linear dynamic was investigated. Two different contact options were studied. In the "with contact" model, the result had been shown that the debonding defect reduced the natural frequencies and altered the deformation shapes of modes studied. It showed that higher natural frequencies were found to be more sensitive to the presence of debonding defects. The "without contact" model showed lower natural frequencies than the "with contact" model which was justified as the incorrect contact modeling. In the time response, the presence of the debonding defect was found to alter the short-term time response. The bigger the debonding ratio, the higher the amplitude of the response. From the investigation, the strain response was one of the most sensitive damage parameters. In the future, the nonlinear debonding modeling combined with the experimental investigation will be carried out to verify further the correctness of the dynamic response to detect the debonding problem in the ship structure.

Acknowledgement: This research is funded by Directorate of Research and Community Services, Ministry of Research, Technology and Higher Education, The Republic of Indonesia under The Master's Degree Program Leading to Doctoral Degree for Excellent Bachelor Graduates (PMDSU) research scheme.

\section{References}

[1] Tuswan, Abdullah K, Zubaydi A, Budipriyanto A. Finite-element Analysis for Structural Strength Assessment of Marine Sandwich Material on Ship Side-shell Structure. Mater. Today: Proceedings. 2017;13(1):109-14. doi:10.1016/j.matpr.2019.03.197.

[2] Carlsson LA, Kardomateas GA. Structural and failure mechanics of sandwich Composites. Gladwell GML, Editors. London New York: Springer Dordrecht; 2011. 386 p.

[3] Triantafllou TC, Gibson LJ. Failure mode maps for foam core sandwich beams. Mater. Sci. and Eng. 1987;95:37-53. doi:10.1016/0025-5416(87)90496-4.

[4] Petras A, Sutcliffe MPF. Failure mode maps for honeycomb sandwich panels. Compos. Struct. 1999;44(4):237-52. doi:10.1016/S0263-8223(98)00123-8.

[5] Burlayenko VN, Sadowski T. Linear and Nonlinear Dynamic Analyses of Sandwich Panels with Face Sheet-to-Core Debonding. Shock. Vib. 2018;2018:1-26. doi:10.1155/2018/5715863.

[6] Zippo A, Ferrari G, Amabili M, Barbieri M, Pellicano F. Active vibration control of a composite sandwich plate. Compos. Struct. 2015;128:100-14. doi:10.1016/j.compstruct.2015.03.037.

[7] Kumar RS, Ray MC. Active damping of geometrically nonlinear vibrations of sandwich plates with fuzzy fiber reinforced composite facings. Int. J. Dynam. Control. 2017;5:314-36. doi:10.1007/s40435-015-0180-3.
[8] Wang JTS, Liu YY, Gibby JA. Vibrations of split beams, J. Sound Vib. 1982;84(4):491-502. doi:10.1016/S0022-460X(82)80030-8.

[9] Tracy JJ, Pardoen GC. Effect of delamination on the natural frequencies of composite laminates. J. Compos. Mater. 1989;23(12):1200-15. doi:10.1177/2F002199838902301201.

[10] Jian SH, Hwu C. Free vibration of delaminated composite sandwich beams. AIAA J. 1995;33(10):1911-18. doi:10.2514/3.12745.

[11] Burlayenko VN, Sadowski T. Influence of skin/core debonding on free vibration behavior of foam and honeycomb cored sandwich plates. Int. J. Non-Linear Mech. 2010;45(10):959-68. doi:10.1016/j.ijnonlinmec.2009.07.002.

[12] Burlayenko VN, Sadowski T. Dynamic behaviour of sandwich plates containing single/multiple debonding. Comput. Mater. Sci. 2011;50(4):1263-68. doi:10.1016/j.commatsci.2010.08.005.

[13] Burlayenko VN, Sadowski T. Numerical Modal Analysis of Sandwich Plates Partially Damaged Due to Impacts. Paper presented at: The $3^{\text {rd }}$ International Conference Nonlinear Dynamics; 2010 September 21-24; Kharkov, Ukraine.

[14] Burlayenko VN, Sadowski T. Transient dynamic response of debonded sandwich plates predicted with finite element analysis. Meccanica. 2014;49:2617-33. doi:10.1007/s11012-014-9924y.

[15] Burlayenko VN, Sadowski T. Finite element nonlinear dynamic analysis of sandwich plates with partially detached facesheet and core. Finite Elem. Anal. Des. 2012;62:49-64. doi:10.1016/j.finel.2012.08.003.

[16] Burlayenko VN, Sadowski T. Nonlinear dynamic analysis of harmonically excited debonded sandwich plates using finite element modelling. Compos. Struct. 2014;108:354-66. doi:10.1016/j.compstruct.2013.09.042.

[17] Luo H, Hanagud S. Dynamics of delaminated beams. Int. J. Solids Struct. 2000;37(10):1501-19. doi:10.1016/S00207683(98)00325-4.

[18] Chakrabarti A, Sheikh AH. Vibration and buckling of sandwich laminates having interfacial imperfections. J. Sandw. Struct. Mater. 2009;11(4):313-28. doi:10.1177/1099636209104514.

[19] Pölöskei T, Szekrényes A. Quasi-periodic excitation in a delaminated composite beam. Compos. Struct. 2017;159:677-88. doi:10.1016/j.compstruct.2016.09.093.

[20] Dassault Systèmes Simulia Corp. Abaqus Analysis User Guide [Internet]: Rhode Island:Dassault Systemes; 2014 [cited August 5 2019]. Available from: http://ivt-abaqusdoc.ivt.ntnu.no:2080/ v6.14/books/usb/default.html.

[21] Burlayenko VN, Sadowski T. Numerical Modeling of Sandwich Plates with Partially edonded Skin-to-Core Interface for Damage Detection. Paper presented at: The $8^{\text {th }}$ International Conference on Structural Dynamics; 2011 July 4-6; Leuven, Belgium.

[22] Krueger R, O'Brien TK. A shell/3D modeling technique for the analysis of delaminated composite laminates. Compos. Part A Appl. Sci. Manuf. 2001;32(1):25-44. doi:10.1016/S1359835X(00)00133-0.

[23] Shen MHH, Grady JE. Free vibrations of delaminated beams. AIAA J. 1992;30(5):1361-70. doi:10.2514/3.11072.

[24] Kwon YW, Lannamann DL. Dynamic numerical modeling and simulation of interfacial cracks in sandwich structures for damage detection. J. Sandw. Struct. Mater. 2002;4(2):175-99. doi:10.1177/1099636202004002706.

[25] Tuswan, Zubaydi A, Budipriyanto A, Sujiatanti SH. Comparative study on ferry ro-ro's car deck structural strength by means of application of sandwich materials. Paper presented at: The $3^{\text {rd }}$ 
International Conference on Marine Technology; 2019 December 5-6; Surabaya, Indonesia.

[26] DNV-GL. Steel sandwich panel construction [Internet]. Norway: DNV-GL; 2016 [cited August 20 2019]. Available from: http://www. dnvgl.com.

[27] Paolozzi A, Peroni I. Detection of debonding damage in a composite plate through natural frequency variations. J. Reinf. Plast. Compos. 1990;9(4):369-88. doi:10.1177/073168 449000900405.
[28] Hou JP, Jeronimidis G. Vibration of delaminated thin composite plates. Compos. Part A Appl. Sci. Manuf. 1999;30(8):989-95. doi:10.1016/S1359-835X(99)00008-1.

[29] Burlayenko VN, Sadowski T. Numerical studies of the dynamic behaviour of sandwich plates initially weakened by the impact damage. Paper presented at: $10^{\text {th }}$ Conference on Dynamical SystemsTheory and Applications; 2009 December 7-10; Lodz, Poland. 